\title{
Investor Sentiment, Mutual Fund Flows and its Impact on Returns and Volatility
}

\author{
Rob Beaumont \\ Radboud University Nijmegen, The Netherlands \\ Bart Frijns* \\ Auckland University of Technology, New Zealand \\ Thorsten Lehnert \\ Maastricht University, The Netherlands \\ Radboud University Nijmegen, The Netherlands \\ Aline Muller \\ Radboud University Nijmegen, The Netherlands
}

*Corresponding Author: Bart Frijns, Department of Finance, Auckland University of Technology, Private Bag 92006, 1020 Auckland, New Zealand. Phone: +64 99219999 ext. 5713; Fax: +64 9921 9876; Email: bfrijns@aut.ac.nz 


\title{
Investor Sentiment, Mutual Fund Flows and its Impact on Returns and Volatility
}

\begin{abstract}
Purpose - This paper investigates the impact of individual investor sentiment on the return process and conditional volatility of three main US market indices (DJIA, S\&P500 and Nasdaq100). Individual investor sentiment is measured by aggregate money flows in and out of domestically oriented US mutual funds.

Design/Methodology/Approach - A GARCH-in-mean specification is used, where our measure for individual sentiment enters the mean and conditional volatility equation.

Findings - For a sample period of six years (February 1998 until December 2004), we find that sentiment has a significant and asymmetric impact on volatility, increasing it more when sentiment is bearish. Using terminology of De Long et al. (1991), we find evidence for the "hold more" effect, which states that when noise traders hold more of the asset, they also see their returns increase, and the "create space" effect, which states that noise traders are rewarded for the additional risk they generate themselves.

Originality - In contrast to existing studies using explicit measures of market sentiment on low sampling frequencies, the use of daily mutual flow data offers a unique picture on investors' portfolio rebalancing and trading behavior. We propose an integrated framework that jointly tests for the effects of mutual fund flows on stock return and conditional volatility.
\end{abstract}

Keywords - Investor Sentiment, Mutual Fund Flows, Behavioral Finance.

Paper type - Research Paper 


\section{Introduction}

The most voluminous set of critique of traditional finance questions the classical view of investors' rationality. Black (1986) laid the foundation by emphasizing the role of noise on a wide range of economic activities, including financial markets. Black contrasts noise with information. In a financial context, information is relevant news about fundamentals of risk and return, whereas noise is irrelevant news. According to his predictions, trading on noise is a vital function that makes the existence and operation of financial markets possible. If there are only trades on information, "taking the other side's information into account, is it still worth trading?" (Black, p. 531). Thus noise trading, defined as trading on noise as if it would be information, provides liquidity to information traders, but it also makes stock prices noisy as they reflect the opinions of noise traders alongside the fundamentals of risk and return. Consequently, prices will be less efficient, which encourages information traders to engage in the market, as they should be able to exploit their informational advantage. However, if their information is already priced, their trading would resemble noise trading, which makes the distinction between both groups blurry. If unsophisticated traders act on noise as if it was value-relevant information, it becomes possible for events such as index inclusions to influence prices and push prices away from the fundamental value. Volatility of prices will thus be greater than volatility of fundamental values and will change over time. In sum, "noise creates the opportunity to trade profitably, but at the same time makes it difficult to trade profitably" (Black, p. 534).

An often-cited, early, theoretical treatment of the impact of noise trading on equilibrium prices is De Long et al. (1990) (DSSW). DSSW distinguish four effects noise trading has on financial markets. In this paper we empirically investigate these effects using a directly observed measure for noise trading. Before we specify our approach we first discuss the effects of noise trading on financial markets.

The first effect is the "create space" effect. If the variability of noise trader sentiment increases, volatility becomes higher. Risk-averse arbitrageurs tend to limit their bets against noise traders, and the expected return to noise trades becomes larger. This effect becomes stronger the larger the proportion of noise traders to arbitrageurs, and the more volatile their misperceptions are. The "Friedman" effect refers to the situation where noise traders have the worst possible market timing, as they tend to herd in their investing behaviour. When noise traders buy when others buy, they tend to buy high and sell low. This has an adverse impact on their returns, which become worse the more volatile noise trader sentiment is. The "hold 
more" effect describes the fact that expected returns can only be higher for noise traders if they are on average bullish about a particular stock. This is because their fluctuating sentiment is a risk that always leads to higher expected returns. However, only if noise traders are on average bullish, they will invest in these securities, and thus earn the additional return. Lastly, the "price pressure" effect states that when bullishness increases, noise traders invest more in the risky asset. This increases demand for the asset, which pushes up its price. Inevitably, higher prices mean lower expected returns, so that their trading activity actually hurts them. Summarizing, the four effects affect expected returns and volatility through different channels, and in opposing directions. While the "hold more" and "price pressure" effects directly influence expected returns, the "Friedman" and "create space" effects are related to the variability of returns, which in turn poses a priced risk and thus has an indirect influence on returns. The "hold more" and "create space" effects work in favour of noise traders' returns, while the "Friedman" and "price pressure" effects are harmful.

To empirically investigate the role of noise trading in financial markets we follow Lee et al. (2002), who offer an empirical specification of De Long et al.'s (1990) theoretical model and simultaneously estimate the impact of noise trader sentiment on the mean and variance in asset returns. In contrast to the Investors' Intelligence of New Rochelle sentiment index utilized in Lee et al. (2002), we make use of daily mutual fund flow data, which has the advantage that it offers a unique picture on investors' portfolio rebalancing and trading behavior. We investigate the relationship between daily mutual fund flows and asset returns between February 1998 and December 2004. The extension of previous work on mutual fund flows in a dynamic framework - focusing on the short and long-run impact of noise trader risk on both first and second moments of returns - provides crucial information on investors' positive or negative feedback trading behavior as well as on the, potentially asymmetric, sensitivity of the conditional volatility of asset returns to sentiment variability. This allows us not only to assess in how far prices may deviate from their true economic value as a function of sentiment-based fund flows, but also to identify the role played by the 'price pressure', 'hold more', 'Friedman' and 'create-space' effects described in De Long et al. (1990) in the fund return-generating process.

The remainder of the paper is organized as follows. In Section 2, we review empirical research on the influence of noise traders on stock prices and discuss several measures that have been used to capture investor sentiment. Section 3 discusses the data and defines the empirical model. In section 4 we discuss our findings, and we conclude the paper in section 5 . 


\section{Literature}

In this section we discuss the literature on individual sentiment indicators. Several financial variables have been used to measure investor sentiment. Brown and Cliff $(2004,2005)$ for example, scrutinize various presumed indirect and direct sentiment indicators. First, we discuss direct measures of private and institutional sentiment. Second, we discuss indirect measures of sentiment, with a special focus on mutual fund flows.

To measure direct sentiment, U.S. oriented research (e.g. Brown and Cliff, 2004 and Fisher and Statman, 2000) has focused on the American Association of Individual Investors (AAII) sentiment index survey and the Investors Intelligence (II) service to distinguish between different classes of investors. Data for both indicators are collected on weekly bases. The AAII sentiment survey measures what percentage of individual investors is bearish, neutral or bullish in the short run. The II captures the appraisement of newsletter writers by classifying the newspapers opinions also as bullish, bearish or neutral. In addition to these sentiment measures, Fisher and Statman also draw on the share of stock recommendation in investment portfolios advised by 15 to 20 Wall Street investment strategists. Correspondingly, they identify three kinds of sentiment, namely: private investors, newspaper writers and institutional investors. Brown and Cliff (2004) also interpret the AAII as an indicator for private investor sentiment. However, they interpret the II as an institutional sentiment indicator. Although similar correlation results are found between the AAII and II, the value of the II as an institutional sentiment indicator, due to the different interpretations, remains ambiguous. It may well be the case that financial journalists represent the private investor feelings and not that of the strategists. Concerning the use of investor sentiment as a stock return predictor, both Fisher and Statman (2000), and Brown and Cliff (2004) predominantly find that sentiment follows stock returns more than it leads them.

Alongside the direct sentiment indicators a vast amount of literature has been developed around indirect sentiment indicators. Indirect sentiment indicators are determined by looking at objective variables that implicitly indicate investor sentiment. Although the theoretical link to investor sentiment is weaker, they circumvent the lack of sample size and statistical representativeness (which and how many subject participate in surveys) of the direct measurements. In addition, measures of indirect sentiment can often be obtained at higher (e.g. daily) frequencies. In the following we discuss several indirect sentiment indicators, such as the closed-end fund discount, the odd-lot balance and mutual fund flows. 
Swaminathan (1996) examines the predictive power of individual investor sentiment on excess expected returns of small firms. Following Lee et al. (1991), he uses an index of closed-end fund discounts to proxy for individual sentiment, and finds that individual investor sentiment, as reflected by closed-end fund discounts, is capable of forecasting small firm returns, even after controlling for dividend yields and term-spreads. He also finds that closedend fund discounts are not able to predict returns on larger companies. His findings therefore confirm the hypothesis of Lee et al., which states that individual investors are major shareholders only in small firms and closed-end funds. The fluctuating discount should therefore reflect the irrational sentiment of individual investors and can forecast small firm returns. However, because closed-end fund discounts seem to be correlated with expectations of future earnings growth and expected inflation, Swaminathan suggests that closed-end fund discounts reflect investors' rational expectations, rather than irrational sentiment.

Contrasting Swaminathan (1996), Elton, Gruber and Busse (1998) find opposing evidence for Lee et al.'s (1991) hypothesis. They show that an index of closed-end fund discounts enters the return-generating process of small firms not more often than expected by chance and even less than purely non-fundamental industry-indices consisting of large, institutionally-held firms. The incorporation of the closed-end fund discount index into an asset pricing model does not yield any support for the hypothesis that this sentiment is priced. Doukas and Milonas (2004) reach the same conclusion when extending the work of Elton et al. to an out-of-sample dataset of Greek closed-end funds and stock market returns. More recently, Wang (2004) again provides opposing evidence that supports the use of closed-end fund discounts as a proxy for sentiment. He constructs portfolios dependent on their exposure to closed-end fund discounts and finds significant excess returns that cannot be explained by traditional asset pricing models such as the Fama and French (1993) three factor model. Whether closed-end fund discounts are appropriate indicators of investor sentiment still remains a discussion and its use as such remains ambiguous.

Kumar and Lee (2003), Jackson (2003), and Kaniel, Saar and Titman (2005) use trading variables to analyze investor sentiment. Kumar and Lee analyze a dataset on individual trading behavior from a major discount broker. They find that the trading behavior of individual clients is correlated, a necessary condition if the activity of individuals is to effect prices. Furthermore, they find that the ratio of shares sold to shares purchased is correlated with the recommendations in newspapers. This sentiment indicator increases the explanatory power for small stocks, value stocks, stocks with low prices and stocks with low 
institutional ownership. This means that when investors are bullish, these stocks show higher excess returns.

Kaniel et al. (2005) analyze individual investors' orders executed on the NYSE. They find that the trading of individuals is a market wide predictor of stock returns. Stocks for which individuals show an increased interest for one week show an average excess return of $1.4 \%$ for the following 20 days. However, the effect seems to be asymmetric, stocks excessively sold by individual investors do not perform worse than average in the following 20 days.

The previously discussed measures of indirect sentiment all focus on the outcomes of actions undertaken by individual investors. In a similar vein, the existence of common factors in the behavior of mutual fund investors has recently motivated researchers to capture market sentiment by mutual fund flows variations and since a couple of years this has become a very popular research field. Goetzmann et al. (1999) were among the first to empirically assess the role played by behavioral factors, such as market sentiment, in the variation of mutual fund flows. The documented negative correlation between daily flows to equity mutual funds, money market funds and precious metal funds suggesting that a significant amount of trade may be explained by investors' continuously rebalancing between cash and equity - their rebalancing decisions not only being generated by liquidity concerns but primarily by market sentiment. ${ }^{1}$

While theory suggests that behavioral factors might well be priced, there is no real consensus on how to measure the sensitivity of asset returns to sentiment-based flows. ${ }^{2}$ Both Goetzmann et al. (1999) and Brown et al. (2002) provide strong empirical evidence in support of mutual fund flows to explain cross-sectional differences in daily realized fund returns. Based on this work, Brown et al. suggest to use mutual fund flows as a measure for investor sentiment and show that the sentiment index they construct is a priced factor in the FamaFrench (1993), Jegadeesh-Titman (1993, 2001) asset pricing framework. The incremental explanatory power of these fund flows opens, however, inevitably the debate on the underlying trading behavior. Without any information on how sentiment is actually driving investors' trading behavior, it is needless to say that it is difficult to determine to what extent changes in investor sentiment may cause prices to deviate from their fundamental value and introduce a systematic risk that is priced. In this perspective, there are at least two apparent drawbacks to the existing empirical literature focusing on the impact of sentiment based mutual fund flows on asset returns. First, the lack of both short- and long-term dynamics in the estimated relationship makes it impossible to infer information on investors' trading 
behavior; and second, in concentrating exclusively on first moments, existing studies fail to address the implications of the variability of market sentiment. This paper addresses these weaknesses explicitly and, in particular, focuses on the dynamics of the influence of noise trading behavior - which may be inferred from fund flows - on asset returns.

\section{Data}

In this section we introduce the data used in this study. We focus on (1) our measure for investor sentiment and (2) on the index returns used.

\subsection{Sentiment: Aggregate Mutual Fund Flows}

As a measure for investor sentiment we use daily aggregate mutual fund flows of domestic U.S. equity funds. We obtain daily mutual fund flow data from TrimTabs (henceforth TT) ${ }^{3}$ for the period February 1998 to December 2004. TT receives net asset values (NAV) and total net assets (TNA) on a daily basis for a large number of US open-end mutual funds (over the entire sample period 1,625 funds have reported to TrimTabs). From these numbers, TT calculates the daily money flows in and out of mutual funds. Funds also report the distribution dates of dividends, but do not always provide details on what fraction of the dividend is actually distributed and what fraction is reinvested. As such, TT advices to treat such distribution dates with caution as $N A V \mathrm{~s}$ may not be correct for such dates. We therefore remove all observations for funds on distribution dates. Second, since data is received by TT through faxes and are hand-keyed by TT staff, typing errors occur in the data. We therefore check all data rigorously for any kind of errors. If an error is found in $N A V \mathrm{~s}$ we consult other data sources (e.g. Morningstar, Yahoo Finance) to obtain information about $N A V$ s. If these are found the $N A V$ is replaced, otherwise the observation is deleted. When $T N A$ are found to be erroneous these observations are removed. This removes most obvious errors in the data set, but not all.

As an additional rigorous check we apply the same filter as proposed by Chalmers et al. (2001). This filter removes all $N A V \mathrm{~s}$ that are more than five standard deviations away from the previous $N A V$. The same rule is applied to TNAs. Chalmers et al. note that such large movements in $N A V$ s have occurred only on few occasions in recent history and are likely caused by data errors. Lastly, we remove all funds that on average have less than $\$ 10$ million in $T N A$, or report less than 60 days to TT. 
From daily $N A V \mathrm{~s}$ and $T N A \mathrm{~s}$, Trimtabs computes the daily in- and outflows for each mutual fund. Fund flows for fund $i$ on day $t$ are computed as

$$
f_{i t}=T N A_{i t}-\mathrm{TNA}_{i t-1} \frac{N A V_{i t}}{N A V_{i t-1}}
$$

where $f_{i t}$ is the flow of fund $i$ at time $t$. The calculation of flows in (1) assumes that reported $T N A$ s include the flow that occurred on day $t$, i.e. they are reported on a post-flow basis. However, recent empirical studies using TT data show that most funds do not incorporate this flow on day $t$ and report their total assets to TT as pre-flow (see Greene and Hodges, 2002; Zitzewitz, 2003). Greene and Hodges argue that more than two thirds of all funds that report to TT actually report pre-flow total assets. Zitzewitz provides evidence that even more funds report on a pre-flow basis. Computing flow as in (1) would therefore result in obtaining flow at time $t-1$. When assets are determined pre-flow, flows can be computed from total assets and $N A V \mathrm{~s}$ by

$$
f_{i t}=\left(T N A_{i t+1}-T N A_{i t} \frac{N A V_{i t+1}}{N A V_{i t}}\right) \frac{N A V_{i t}}{N A V_{i t+1}}
$$

Apart from a discount factor, this entails that flows reported by TT are actually the flow at $t-1$ when TNA are pre-flow.

Given the evidence provided by Greene \& Hodges (2002) and Zitzewitz (2003) we treat all $T N A$ s as pre-flow, and compute daily flows as given in (2). This clearly leads to some errors for flows that are reported on a post-flow basis. For those funds we would actually be using the one day lead flow in the analysis.

TrimTabs receives figures on $N A V \mathrm{~s}$ and $T N A \mathrm{~s}$ for various types of mutual funds. We sort mutual funds into fund categories based on the prospectus objective stated by the fund (information obtained from Wiesenberg and Morningstar) and retain all flows for funds that classify as domestic equity funds (706 funds). For these domestic equity funds we construct four measures of average daily flow that will serve as a measure for sentiment. These are equally- and value weighted average flows per day ( $E W F$ and $V W F$, respectively) and normalized equally- and value weighted average flows per day ( $N E W F$ and $N V W F$, respectively). The latter two series are computed by normalizing each individual flow by the size of the fund. Summary statistics of the flow data are reported in table 1. 
Table I: Summary Statistics Sentiment Indices

\begin{tabular}{lllll}
\hline \hline & \multicolumn{4}{c}{ Sentiment Indices } \\
\cline { 2 - 5 } Mean & EWF & VWF & NEWF & NVWF \\
Median & -0.019 & 0.32 & -0.000184 & -0.000079 \\
Max. & -0.109 & -0.25 & -0.000241 & -0.000113 \\
Min. & 4.48 & 22.95 & 0.00380 & 0.00297 \\
St. Dev. & -4.36 & -33.13 & -0.00470 & -0.00331 \\
Skewness & 1.13 & 4.28 & 0.00105 & 0.00082 \\
Kurtosis & 0.41 & -0.09 & 0.25 & 0.16 \\
Jarque-Bera Statistic & 4.85 & 9.76 & 4.64 & 4.47 \\
& $295.43^{* * *}$ & $3289.94^{* * *}$ & $212.51^{* * *}$ & $163.52^{* * *}$ \\
ADF Statistic & & & & \\
& $-6.74^{* * *}$ & $-6.04^{* * *}$ & $-10.74^{* * *}$ & $-8.96^{* * *}$ \\
Autocorrelations & & & & \\
\hline Lag 1 & & & & \\
Lag 2 & $-0.060^{* *}$ & $0.239^{* * *}$ & $-0.076^{* * *}$ & -0.014 \\
Lag 3 & $-0.090^{* * *}$ & $0.222^{* * *}$ & $-0.082^{* *}$ & -0.011 \\
\hline Nates This tab pros & -0.015 & $0.262^{* * *}$ & 0.007 & 0.065 \\
\hline
\end{tabular}

Notes: This table presents summary statistics for the various measures of investor sentiment. We construct four different measures for investor sentiment from daily mutual fund flow data: equally- and valueweighted average daily fund flow (EWF and VWF), and normalized equally- and value-weighted average daily fund flow (NEWF and NVWF). Significance of statistics is indicated by ${ }^{*}$, where ${ }^{*}$ indicates significance at the $10 \%$ level, ${ }^{* *}$ indicates significance at $5 \%$ and ${ }^{* * *}$ indicates significance at $1 \%$.

From the mean and median of the series (except for VWF) we observe that money flow into US domestic mutual funds has been negative. We further observe that none of the measures for sentiment are normally distributed. The Jarque-Bera statistic rejects normality at the $1 \%$ level for each series. This non-normality is most severe for the VWF series, which has very high kurtosis (9.76) and very high maximum and minimum values in comparison to the EWF series. Interestingly, non-normality is the lowest for the NVWF series. In this case the value-weighted index has a lower skewness and kurtosis than the equally-weighted index. All series are stationary as indicated by the highly significant Augmented Dickey-Fuller statistics. Finally, we report autocorrelations for all series up to three lags. We observe some significance in the autocorrelations in the series, most prevalent and persistent for the VWF index. In all other cases we find small, short-lived, negative autocorrelations, which in some cases are significant. 
Table II: Summary Statistics Excess Returns

\begin{tabular}{|c|c|c|c|}
\hline \multirow[b]{3}{*}{ Mean (x1000) } & \multicolumn{3}{|c|}{ Excess Returns } \\
\hline & DJIA & S\&P500 & Nasdaq100 \\
\hline & 1.2478 & 0.5256 & 1.1017 \\
\hline Median (x1000) & 2.4711 & 1.6940 & 12.8064 \\
\hline $\operatorname{Max}$ & 0.0615 & 0.0557 & 0.1718 \\
\hline Min. & -0.0735 & -0.0706 & -0.1040 \\
\hline St. Dev. & 0.0122 & 0.0126 & 0.0255 \\
\hline Skewness & -0.10 & 0.01 & 0.18 \\
\hline Kurtosis & 5.95 & 5.02 & 5.47 \\
\hline Jarque-Bera Statistic & $629.83^{* * *}$ & $295.42^{* * *}$ & $448.16^{* * *}$ \\
\hline \multicolumn{4}{|l|}{ Autocorrelation } \\
\hline $\operatorname{Lag} 1$ & -0.015 & -0.019 & $-0.062^{* *}$ \\
\hline $\operatorname{Lag} 2$ & -0.023 & -0.025 & $-0.061^{* *}$ \\
\hline $\operatorname{Lag} 3$ & -0.006 & -0.026 & 0.05 \\
\hline \multicolumn{4}{|c|}{$\begin{array}{l}\text { Notes: This table presents summary statistics for the excess market returns. We use three different indices to } \\
\text { compute these excess returns, the Dow Jones Industrial Average (DJIA), the S\&P500 and the Nasdaq100. } \\
\text { Significance of statistics is indicated by }{ }^{*} \text {, where }{ }^{*} \text { indicates significance at the } 10 \% \text { level, }{ }^{* *} \text { indicates } \\
\text { significance at } 5 \% \text { and }{ }^{* * *} \text { indicates significance at } 1 \% \text {. }\end{array}$} \\
\hline
\end{tabular}

The summary statistics presented above give us some indication of the applicability of the series as a sentiment indicator. Most likely, the VWF index will perform poorly, given its high non-normality and persistent autocorrelation. The best fits are expected for the normalized indices as these are closest to normality and are not affected by flows into a few large funds.

\subsection{Stock Price Indices}

In addition to fund flows, we obtain daily data for three main US market indices for the same period (February 1998 to December 2004) from Datastream. Similar to Lee et al. (2002) we obtain data for the Dow Jones Industrial Average (DJIA), the S\&P500 and the Nasdaq100. We also obtain the 90-day T-bill rates from Datastream to proxy the risk-free rate. For each index we compute the excess return over the risk-free rate. Some summary statistics for these excess returns are presented in Table 2.

Over the whole sample period, returns have been positive as indicated by the means and the medians. Interestingly, we find that returns were highest for the DJIA index, which came at the lowest volatility. Volatility was highest for the Nasdaq100. None of the return 
indices are normally distributed (normality is again rejected by the Jarque-Bera statistic at the $1 \%$ level) and all indices display excess kurtosis. Returns are slightly negatively skewed for DJIA, slightly positively skewed for the Nasdaq100, and the S\&P500 displays almost no skewness. As expected in efficient markets, almost none of the autocorrelations are significant, except for the Nasdaq100 index, which displays significant negative autocorrelation for up to two lags.

\section{Methodology}

In determining how investor sentiment affects market volatility and stock price returns we use a GARCH-in-mean specification similar to Lee et al. (2002). This specification allows the assessment of two relationships on how investor sentiment affects returns and volatility. The first relationship considers the direct impact of investor sentiment on excess market returns. The directional impact sentiment has on these excess returns follows from two effects suggested by the De Long et al. (1990), the "hold more" effect and the "price pressure" effect. The first effect relates to the hypothesis that noise traders hold proportionately more of the risky asset than the sophisticated fundamentalists, when bullish on average. Since noise traders bear more of the risk in the market, they also expect a higher return. On the other hand when average sentiment is bearish, noise traders hold less of the risky asset and therefore require a lower expected return. If this hypothesis holds, we expect to see a positive relationship between excess returns and investor sentiment. The second effect, the "price pressure" effect, has a moderating effect on the first one. This effect states that when noise traders are on average bullish they increase their demand for the risky asset, thus pushing up prices. However, when prices increase, expected return goes down. Similarly, when sentiment is bearish, noise trader demand for the risky asset drops, which decreases prices and increases expected returns. The latter effect therefore expects a negative relationship between sentiment and excess returns.

To measure both effects, we use the following specification for the mean equation

$$
r_{t}-r_{f t}=\alpha_{0}+\alpha_{1} \sigma_{t}+\alpha_{2} S_{t}+\alpha_{2} S_{t-1}+\varepsilon_{t}
$$

where $r_{t}$ measures the daily return on one of the stock market indices (DJIA, S\&P500, or Nasdaq100), $r_{f t}$ measures the risk-free rate as proxied by the 90-day T-bill rate, $S_{t}$ measures the investor sentiment for each of the different indices (EWF, VWF, NEWF, or NVWF), and 
$\sigma_{t}$ measures the conditional volatility of the market index. The two coefficients on the measure for investor sentiment (aggregate fund flow and lagged aggregate fund flow) will indicate the importance of both effects. When $\alpha_{1}$ and $\alpha_{2}$ are both positive, this provides evidence for the "hold more" effect dominating. When both are negative it provides evidence for the "price pressure" effect. Finally, the model also allows us to observe whether the price pressure effect would follow the hold more effect. If bullish sentiment encourages noise traders to hold more of the risky asset, we expect a positive contemporaneous relationship. However, when excess demand contemporaneously pushes up prices, it could mean that future returns decrease. In that case we expect a negative relationship with the lagged sentiment.

The second relationship considers how the conditional volatility affects the excess returns of the market indices, where the conditional volatility is affected by the variance in investor sentiment. Again we distinguish between two different effects that affect this relationship. The first effect has become known as the "Friedman" effect, which refers to the notion that noise traders trade at the worst time possible, i.e. they buy high and sell low. This effect increases the volatility in the market and decreases the return to noise traders. The second effect, known as the "create space" effect, relates to the notion that noise traders increase risk by their own trading and are rewarded for that risk. The effect entails that when the variability in noise traders' beliefs increases, this increases the volatility of the market. This increased variability in noise traders' beliefs scares away sophisticated traders in the market and therefore increases the expected return to the noise traders. The importance or dominance of a particular effect can again be inferred from the model. We include variability in investor's sentiment in the specification for the conditional volatility of the model,

$$
\sigma_{t}^{2}=\beta_{0}+\beta_{1} \varepsilon_{t-1}^{2}+\beta_{2} \varepsilon_{t-1}^{2} I_{t-1}+\beta_{3} \sigma_{t-1}^{2}+\beta_{4} S_{t-1}^{2} D_{t-1}+\beta_{5} S_{t-1}^{2}\left(1-D_{t-1}\right)
$$

where $I_{t-1}=1$, when $\varepsilon_{t-1}<0$ and zero otherwise, and $D_{t-1}=1$ when $S_{t-1}>0$ and zero otherwise. The hypothesis of whether investor sentiment affects the conditional volatility of the market indices can be inferred from the significance of the coefficients $\beta_{4}$ and $\beta_{5}$. Whether this volatility in turn affects the excess return is measured by the GARCH-in-mean term $\alpha_{1}$ in (3). If this coefficient is significantly positive, it provides evidence for the "create space", whereas if this coefficient is significantly negative, it provides evidence for the "Friedman" effect. 
In addition to the effects mentioned above, we consider a few other factors that can affect the conditional volatility. Firstly, we allow for asymmetry in the ARCH term of (2). This asymmetry is motivated by Nelson (1991) who finds that the arrival of good or bad news has an asymmetric impact on the conditional variance. Given the definition of $I_{t}$, we expect $\beta_{2}$ to be positive as negative news generally increases volatility more than good news. In a similar vein we allow for asymmetry in the impact of sentiment on the conditional variance. In this case our interest is in observing whether the variability in investor sentiment has a different impact on this variance when the market is on average bullish or bearish. The signs and magnitudes of the coefficients $\beta_{4}$ and $\beta_{5}$ will provide answer to this question.

\section{Empirical Results}

In this section we present the results for the model proposed in the previous section and we discuss the implications of the model for the previously stated hypotheses. All models are estimated using Quasi-Maximum Likelihood, where standard errors are adjusted for heteroskedasticity (Bollerslev and Wooldridge, 1992).

In panel A of Table 3 we present the results for the models using the DJIA in the calculation of the excess returns. The first column in this panel presents the benchmark regression excluding the sentiment indicator. We observe a positive, but insignificant GARCH-in-mean term. Turning to the coefficients in the conditional volatility equation, we find that the ARCH-term is only significant for negative shocks, in this case the conditional volatility increases substantially. Apart from this relationship the ARCH-term is insignificant.

The second column presents the results for the model using equally-weighted average flow as a proxy for sentiment. The inclusion of this sentiment indicator improves the model considerably as can be seen from the highly significant Likelihood Ratio statistic. ${ }^{4}$ In the mean equation we observe that the addition of sentiment and lagged sentiment are both significant at the $1 \%$ level. Both show positive coefficients, providing strong evidence for the "hold more" effect. These findings are in line with Lee et al. (2002). In the conditional volatility equation we find that the variability in lagged sentiment is only significant when sentiment is bullish, in this case the variability in sentiment decreases volatility significant. Finally, we find a weakly significant (at the 10\% level) and positive GARCH-in-mean term, providing some evidence for the "create space" effect, i.e. increasing volatility due to changes in sentiment increases the expected return to noise traders. This finding contrasts the findings of Lee et al. who find a negative relationship and thus evidence for the "Friedman" effect. 
Table III: GARCH models

\begin{tabular}{|c|c|c|c|c|c|}
\hline \multicolumn{3}{|l|}{ Panel A: DJIA } & \multirow[b]{2}{*}{$\left(S_{t}=V W F_{t} \times 1000\right)$} & \multirow[b]{2}{*}{$\left(S_{t}=N E W F_{t}\right)$} & \multirow[b]{2}{*}{$\left(S_{t}=N V W F_{t}\right)$} \\
\hline & $\left(S_{t}=0\right)$ & $\left(S_{t}=E W F_{t} \times 1000\right)$ & & & \\
\hline$\alpha_{0}$ & -0.0008 & $-0.0016^{*}$ & -0.0003 & -0.0002 & -0.0015 \\
\hline$\sigma_{t}$ & 0.0862 & $0.1880^{*}$ & 0.0253 & 0.1068 & $0.2167^{* *}$ \\
\hline$S_{t}$ & & $3.9194^{* * *}$ & $0.7529^{* * *}$ & $4.8481^{* * *}$ & $6.0501^{* * *}$ \\
\hline$S_{t-1}$ & & $1.3094^{* * *}$ & -0.02 .04 & $1.4249^{* * *}$ & $1.4983^{* * *}$ \\
\hline$\beta_{0}\left(x 10^{-6}\right)$ & $2.10^{* * *}$ & $2.74^{* * *}$ & $1.61^{* * *}$ & $2.60^{* * *}$ & $2.89^{* * *}$ \\
\hline$\varepsilon_{t-1}^{2}$ & -0.0039 & 0.0140 & 0.0019 & $0.0408^{* *}$ & 0.0239 \\
\hline$\varepsilon_{t-1}^{2} I_{t-1}$ & $0.1298^{* * *}$ & $0.1003^{* * *}$ & $0.1062^{* * *}$ & $0.0673^{* *}$ & $0.0699^{* * *}$ \\
\hline$\sigma_{t-1}^{2}$ & $0.9243^{* * *}$ & $0.9131^{* * *}$ & $0.9290^{* * *}$ & $0.8888^{* * *}$ & $0.9069^{* * *}$ \\
\hline$S_{t-1}^{2} D_{t-1}$ & & $-1.2187^{* *}$ & -0.0319 & $-2.0472^{* *}$ & $-3.3414^{* * *}$ \\
\hline$S_{t-1}^{2}\left(1-D_{t-1}\right)$ & & 1.1552 & $0.1260^{* *}$ & $3.9192^{* * *}$ & $5.3286^{* *}$ \\
\hline Log likelihood & 5358.79 & 5532.41 & 5434.94 & 5563.16 & 5549.86 \\
\hline LR Statistic & & $347.24^{* * *}$ & $152.30^{* * *}$ & $408.74^{* * *}$ & $382.14^{* * *}$ \\
\hline \multicolumn{3}{|c|}{ Panel B: S\&P500 } & \multirow[b]{2}{*}{$\left(S_{t}=V W F_{t} \times 1000\right)$} & \multirow[b]{2}{*}{$\left(S_{t}=N E W F_{t}\right)$} & \multirow[b]{2}{*}{$\left(S_{t}=N V W F_{t}\right)$} \\
\hline & $\left(S_{t}=0\right)$ & $\left(S_{t}=E W F_{t} \times 1000\right)$ & & & \\
\hline$\alpha_{0}$ & -0.0010 & $-0.0027^{* * *}$ & -0.0001 & -0.0006 & $-0.0028^{* * *}$ \\
\hline$\sigma_{t}$ & 0.0893 & $0.2879^{* * *}$ & -0.0028 & $0.2015^{*}$ & $0.3609^{* * *}$ \\
\hline$S_{t}$ & & $4.9841^{* * *}$ & $0.9303^{* * *}$ & $5.9647^{* * *}$ & $7.5632^{* * *}$ \\
\hline$S_{t-1}$ & & $1.5444^{* * *}$ & -0.0519 & $1.6149^{* * *}$ & $1.8370^{* * *}$ \\
\hline$\beta_{0}\left(x 10^{-6}\right)$ & $2.41^{* * *}$ & $4.46^{* * *}$ & $1.61^{* * *}$ & $4.16^{* * *}$ & $4.65^{* * *}$ \\
\hline$\varepsilon_{t-1}^{2}$ & $-0.0263^{* *}$ & 0.0204 & -0.0070 & $0.0532^{* *}$ & $0.0364^{* *}$ \\
\hline$\varepsilon_{t-1}^{2} I_{t-1}$ & $0.1553^{* * *}$ & $0.1117^{* * *}$ & $0.1196^{* * *}$ & $0.0788^{* * *}$ & $0.0683^{* *}$ \\
\hline$\sigma_{t-1}^{2}$ & $0.9326^{* * *}$ & $0.8859^{* * *}$ & $0.9654^{* * *}$ & $0.8536^{* * *}$ & $0.8783^{* * *}$ \\
\hline$S_{t-1}^{2} D_{t-1}$ & & $-1.6017^{* * *}$ & $-0.0631^{* *}$ & $-2.6736^{* * *}$ & $-4.7077^{* * *}$ \\
\hline$S_{t-1}^{2}\left(1-D_{t-1}\right)$ & & 1.1306 & $0.1102^{* *}$ & $4.6225^{* * *}$ & $6.2522^{* * *}$ \\
\hline Log likelihood & 5296.30 & 5565.32 & 5395.69 & 5587.83 & 5571.62 \\
\hline LR Statistic & & $538.04^{* * *}$ & $198.78^{* * *}$ & $583.06^{* * *}$ & $550.64^{* * *}$ \\
\hline
\end{tabular}




\begin{tabular}{|c|c|c|c|c|c|}
\hline \multicolumn{6}{|c|}{ Table III Continued... } \\
\hline \multicolumn{3}{|c|}{ Panel C: Nasdaq100 } & \multirow[b]{2}{*}{$\left(S_{t}=V W F_{t} \times 1000\right)$} & \multirow[b]{2}{*}{$\left(S_{t}=N E W F_{t}\right)$} & \multirow[b]{2}{*}{$\left(S_{t}=N V W F_{t}\right)$} \\
\hline & $\left(S_{t}=0\right)$ & $\left(S_{t}=E W F_{t} \times 1000\right)$ & & & \\
\hline$\alpha_{0}$ & 0.0004 & 0.0023 & $0.0033^{* *}$ & $0.0056^{* * *}$ & 0.0020 \\
\hline$\sigma_{t}$ & -0.0055 & -0.0904 & $-0.1665^{* *}$ & $-0.1554^{*}$ & -0.0257 \\
\hline$S_{t}$ & & $9.7247^{* * *}$ & $2.0359^{* * *}$ & $10.4443^{* * *}$ & $13.7162^{* * *}$ \\
\hline$S_{t-1}$ & & $2.1389^{* * *}$ & -0.1539 & $1.9343^{* * *}$ & $1.9654^{* * *}$ \\
\hline$\beta_{0}\left(x 10^{-6}\right)$ & $3.48^{* *}$ & $4.77^{* *}$ & 1.82 & $4.29^{* * *}$ & $9.41^{* * *}$ \\
\hline$\varepsilon_{t-1}^{2}$ & 0.0248 & $0.0317^{* *}$ & 0.0154 & $0.0316^{* *}$ & $0.0314^{*}$ \\
\hline$\varepsilon_{t-1}^{2} I_{t-1}$ & $0.0765^{* *}$ & $0.0675^{* * *}$ & $0.0599^{*}$ & $0.0681^{* * *}$ & $0.0898^{* * *}$ \\
\hline$\sigma_{t-1}^{2}$ & $0.9315^{* * *}$ & $0.9207^{* * *}$ & $0.9465^{* * *}$ & $0.9156^{* * *}$ & $0.8891^{* * *}$ \\
\hline$S_{t-1}^{2} D_{t-1}$ & & -2.3494 & 0.0055 & $-4.4320^{*}$ & $-9.4632^{* *}$ \\
\hline$S_{t-1}^{2}\left(1-D_{t-1}\right)$ & & $4.8584^{*}$ & $0.3728^{*}$ & $9.3895^{* *}$ & $22.9245^{* * *}$ \\
\hline Log likelihood & 4137.53 & 4392.58 & 4260.21 & 4387.15 & 4388.25 \\
\hline LR Statistic & & $510.10^{* * *}$ & $245.36^{* * *}$ & $499.24^{* * *}$ & $501.44^{* * *}$ \\
\hline
\end{tabular}

Notes: This table presents the results for the GARCH-in-mean model specified in equations (3) and (4). Panel A reports results for model using the DJIA index as dependent variable, panel B for the model using the S\&P500 index as dependent variable and panel $\mathrm{C}$ for the Nasdaq100 index as dependent variable. The first column in each panel reports the benchmark model without the inclusion of the sentiment index, the next four columns report results including the different measures for sentiment used. Standard error are heteroskedasticity consistent and significance is indicated by ${ }^{*},{ }^{* *}$ and ${ }^{* * *}$ for the $10 \%, 5 \%$, and $1 \%$ level, respectively. Likelihood ratio statistics are Chi-squared distributed with 4 degrees of freedom and have critical values of 14.9 at the $1 \%$ level.

In the last three columns we present results for the other proxies of investor sentiment. Overall, results are the same for all different proxies, i.e. we find evidence for the "hold more effect" in all cases and some evidence for the "create space effect". When using VWF as sentiment indicator, however, the fit of the model is substantially lower than for the other sentiment proxies. This is likely attributable to the high kurtosis and large non-normality of this series. We finally note that for the normalized sentiment indicators we find that sentiment is significant in the conditional volatility equation and that variability in sentiment has the largest impact on volatility (increasing it) when the market is bearish on average.

In Panel B of table 3 we present the results using the S\&P500 index as the excess return. The benchmark regression reveals the same pattern as observed for the DJIA as index. The overall ARCH-term is significantly negative, but again we find a large and strongly significant asymmetry in the ARCH-term. Again volatility increases substantially when negative shocks occur. When including the various proxies for sentiment we note a significant 
increase in likelihood of the model in all cases. Again the increase is largest for the normalized flow variables and lowest for VWF. The regressions again provide strong evidence for the "hold more" effect, as most coefficients in the mean equation on sentiment and lagged sentiment are positive and significant. In addition, we also find strong evidence for the "create space" effect as the coefficients on the GARCH-in-Mean term are mostly positive and significant. Lastly, we find a more pronounced role of sentiment in the determination of the conditional volatility. In most cases sentiment significantly affect volatility and to a larger extend than for the DJIA index. Again we find a strong asymmetric reaction of volatility to sentiment. When investors are bearish, volatility increases more than when investors are bullish.

Finally, panel $\mathrm{C}$ reports the results for the models using the Nasdaq100 as the dependent variable. The benchmark regression show similar results as shown before and again we find that the inclusion of the sentiment proxies increases the likelihood of the model significantly. Similar to the previous results we again find evidence for the "hold more" effect, most coefficients on current and lagged sentiment are significantly positive. However, contrasting the previous findings we now find evidence for the "Friedman" effect. All coefficients on the GARCH-in-Mean term are negative and in some cases significant. Sentiment again shows an asymmetric impact on volatility, which, for the normalized flow series is even more pronounced than for DJIA and S\&P500.

Overall, the findings for the different indices provide strong support for the "hold more" effect, which confirms findings of Lee et al. (1992). In determining the impact of conditional volatility on excess returns our findings are less decisive. Using the DJIA and S\&P500 as the dependent variables we find evidence for the "create space" effect, whereas when using the Nasdaq100 we find evidence for the "Friedman" effect.

\section{Conclusion}

In this paper, we propose an integrated framework that jointly tests for the effects of sentiment on stock return and conditional volatility. We use daily aggregate mutual fund flows of domestic US equity funds as a measure for investor sentiment. We empirically investigate the relationship with the three major US market indices, DJIA, S\&P500 and Nasdaq100, over the period February 1998 until December 2004.

We confirm previous findings regarding the incremental explanatory power of investor sentiment for stock returns. In line with Lee et al. (2002), we find a strong positive 
relationship of sentiment-based fund flows and market returns for all indices. In determining the impact of conditional volatility on excess returns our findings are less decisive. For the large cap portfolios, the DJIA and S\&P500, we find evidence for the "create space" effect, the positive relationship between the expected return and the risk caused by the increased variability of noise trader sentiment. This effect typically becomes stronger the more noise traders in relation to arbitrageurs are trading in a particular market. Results suggest that the "Friedman" effect is more important for the small cap portfolio of Nasdaq100 stocks. Noise traders have the worst possible market timing, as they tend to herd in their investing behaviour. This of course has a negative impact on the expected returns, which becomes worse, the more volatile noise trader sentiment is.

\section{Notes}

1. Further evidence that fund flows reflect shifting investor sentiment is provided by Grinblatt and Keloharju (2000).

2. The fact that both individual and institutional sentiment is a priced factor in market equilibrium is a matter still in dispute. See, for instance, the contradicting conclusions in Brown and Cliff (1999) and Elton et al. (1998).

3. For detailed discussions about the nature of TrimTabs fund flow data, including issues regarding timing of flows, we refer to Greene \& Hodges (2002), Chalmers et al. (2001), and Zitzewitz (2003).

4. Likelihood ratio statistics test the difference between the models excluding sentiment and the models including sentiment.

\section{References}

Black, F. (1986), “Noise”, Journal of Finance, Vol. 16, pp. 529-543.

Bollerslev, T. and Wooldridge, J. M. (1992), "Quasi-maximum likelihood estimation and inference in dynamic models with time varying covariances," Econometrics Review, Vol. 11, pp. $143-172$. 
Brown, G. W. and Cliff, M. T. (2004), "Investor sentiment and the near-term stock market," Journal of Empirical Finance, Vol. 11, pp. 1-27.

Brown, G. W. and Cliff, M. T. (2005), "Investor sentiment and asset valuation," Journal of Business, Vol. 78, pp. 405-440.

Brown, S. J., Goetzmann, W. N., Hiraki, T., Shiraishi, N. and Watanabe, M. (2002), "Investor sentiment in japanese and U.S. daily mutual fund flows," Yale ICF Working Paper No. 02-09; AFA 2003 Washington, DC Meetings.

Chalmers, J. M. R., Edelen, R.M. and Kadlec, G. B. (2001), "On the perils of financial intermediaries setting security prices: the mutual fund wild card option," Journal of Finance, Vol. 56, pp. 2209 - 2236.

De Long, J. B., Shleifer, A., Summers, L. G. and Waldman, R. J. (1990), "Noise trader risk in financial markets," Journal of Political Economy, Vol. 98, pp. 703 - 738.

Doukas, J. A. and Milonas, N. T. (2004), "Investor sentiment and the closed-end fund puzzle: out-of-sample evidence,” European Financial Management, Vol. 10, pp. 235-267.

Elton, E. J., Gruber, M. J. and Busse, J. A. (1998), "Do investors care about sentiment?," Journal of Business, Vol. 71, pp. 477-500.

Fama, E. F. and French, K. R. (1993), "Common risk factors in the returns on bonds and stocks," Journal of Financial Economics, Vol. 33, pp. 3-56.

Fisher, K. L. and Statman, M. (2000), "Investor sentiment and stock returns," Financial Analysts Journal, Vol. 56, pp. 16-24.

Goetzmann, W. N., Massa, M. and Rouwenhorst, K. G. (1999), "Behavioral factors in mutual fund flows," Yale ICF Working Paper No. 00-14.

Greene, J. T. and Hodges, C. W. (2002), “The dilution impact of daily fund flows on openend funds," Journal of Financial Economics, Vol. 65, pp. 131-158. 
Grinblatt, M. and Keloharju, M. (2000), "The investment behavior and performance of various investor types: a study of Finland's unique data set," Journal of Financial Economics, Vol. 55, pp. 43-67.

Jackson, A. (2003), "The aggregate behaviour of individual investors," Working paper, London Business School.

Jegadeesh, N. and Titman, S. (1993), "Returns to buying winners and selling losers: implications for stock market efficiency," Journal of Finance, Vol. 48, pp. 65-91.

Jegadeesh, N. and Titman, S. (2001), "Profitability of momentum strategies: an evaluation of alternative explanations," Journal of Finance, Vol. 56, pp. 699-720.

Kaniel, R., Saar, G. and Titman, S. (2004), "Individual investor sentiment and stock returns," Working Paper, Stern School of Business, New York.

Kumar, L. and Lee, C. M. (2003), "Individual investor sentiment and comovement in small stock returns," Working Paper, Department of Economics, Cornell University.

Lee, C. M. C., Shleifer, A. and Thaler, R. H. (1991), "Investor sentiment and the closed-end fund puzzle," Journal of Finance, Vol. 64, pp. 75-110.

Lee, W. Y., Jiang, C. X. and Indro, D.C. (2002), "Stock market volatility, excess returns, and the role of investor sentiment," Journal of Banking and Finance, Vol. 26, pp. 2277-2299.

Nelson, D. B. (1991), "Conditional heteroscedasticity in asset returns: a new approach," Econometrica, Vol. 59, pp. 347-370.

Swaminathan, B. (1996), "Time-varying expected small firm returns and closed-end fund discounts," Review of Financial Studies, Vol. 9, pp. 845-887.

Wang, X. (2004), “Sentiment strategies," Working Paper, University of Michigan at Ann Harbour.

Zitzewitz, E. (2003), "Who cares about shareholders? Arbitrage-proofing mutual funds," Journal of Law, Economics and Organization, Vol. 19, pp. 245-280. 